haematospermia. Andrology, 1(6), 948-956.

5. Ganabathi, K., Chadwick, D., Feneley, R. C. L., \& Gingell, J. C. (1992). Haemospermia. British Journal of Urology, 69(3), 225-230.pdf.

6. Zargooshi J., Nourizad S., Vaziri S. và cộng sứ. (2014). Hemospermia: long-term outcome in 165 patients. Int J Impot Res, 26(3), 83-86.
7. Akhter W., Khan F., và Chinegwundoh F. (2013). Should every patient with hematospermia be investigated? A critical review. Cent Eur J Urol 66(1), 79-82.

8. Yagci C., Kupeli S., Tok C. và cộng sự. (2004). Efficacy of transrectal ultrasonography in the evaluation of hematospermia. Clin Imaging, 28(4), 286-290.

\title{
NGHIÊN CỨU GÁNH NẶNG CHĂM SÓC BÊNNH NHÂN ALZHEIMER TẠI BÊ̂NH VIỆN LÃO KHOA TRUNG ƯO'NG NĂM 2020 - 2021
}

\section{TÓM TẮT}

Mục tiêu: Mô tả gánh nặng chăm sóc bệnh nhân Alzheimer và một số yếu tố liên quan. Đối tượng và phương pháp: Nghiên cứu mô tả cắt ngang gánh nặng chăm sóc dựa trên thang điểm Zazit ở 52 người chăm sóc bệnh nhân Alzheimer tại Bệnh viện Lão Khoa Trung ương từ năm 2020 đến năm 2021. Kết quả: Gánh nặng chăm sóc trung bình của người chăm sóc theo thang điểm Zarit là 42,7 điểm. Trong đó, $57,7 \%$ trường hợp gánh nặng ở mức độ nghiêm trọng và rất nghiêm trọng. Gánh nặng chămm sóc có xu hướng tăng dần có ý nghĩa thống kê $(\mathrm{p}<0,05)$ theo thời gian chăm sóc bệnh nhân/ngày; thời gian mắc bệnh; giai đoạn sa sút trí tuệ; sự xuất hiện triệu chứng các triệu chứng giảm nhận biết, giảm sự chú ý, giảm tư duy, tính toán, giảm ngôn ngữ và hoạt động hàng ngày và các triệu chứng BPSD như hoang tưởng, kích động, mất ức chế, rối loạn vận động, rối loạn ăn uống và hành vi ban đêm. Kết luận: Gánh nặng chăm sóc bênh nhân Alzheimer của người chăm sóc là 42,7 điểm theo thang Zarit và có liên quan có ý nghĩa thống kê đến một số đặc điểm và mức độ nặng của triệu chứng bệnh.

Tư khóa: Alzheimer, gánh nặng chăm sóc, thang điểm Zarit.

\section{SUMMARY}

\section{THE CAREGIVER BURDEN OF PATIENTS WITH} ALZHEIMER'S DISEASE AT NATIONAL GERIATRIC HOSPITAL FROM 2020 TO 2021

Objective: Describe the burden of caring with Alzheimer's patients and related factors. Methods: A cross-sectional descriptive study about carving burden using ZBI on 52 caregivers of Alzheimer's patients at National Geriatric Hospital from 2020 to 2021. Results: The average caregiver burden on the ZBI is 42.7 points. In which, $57.7 \%$ of cases are severe and

\footnotetext{
${ }^{1}$ Bệnh viện Lão khoa Trung ương

2Trường Đai hoc Thăng Long

Chịu trách nhiệm chính: Nguyễn Ngọc Ánh

Email: ngocanh.nig@gmail.com

Ngày nhận bài: 19.3.2021

Ngày phản biên khoa hoc: 11.5.2021

Ngày duyệt bài: 21.5.2021
}

\section{Nguyễn Ngọc Ánh ${ }^{1}$, Đỗ Thị Khánh Hỳ 1,2}

very severe. The burden of care tends to increase with statistical significance $(p<0.05)$ according to the time of patient care/day; disease duration; stage of dementia; the occurrence of symptoms of reduced awareness, decreased attention, decreased thinking, reduced calculation, decreased language and daily functioning, and BPSD symptoms such as delusions, agitation, loss of inhibitions, dyskinesia, eating disorders and nocturnal behavior. Conclusions: Caregiver's burden of care with Alzheimer's is 42.7 ZBI and significantly associated with several characteristics and symptom severity.

Key words: Alzheimer, burden of caregiver, Zarit Burden Interview

\section{I. ĐĂT VẤN ĐỀ}

Ngày nay, sự già hóa dân số có xu hướng ngày càng tăng kéo theo sự gia tăng tỷ lệ mắc các bệnh thoát hóa, trong đó có sa sút trí tuệ. Theo tổ chức $Y$ tế thế giới WHO ước tính có 50 triệu người mắc sa sút trí tuệ năm 2018, khoảng 10 triệu trường hợp mới mẳc hàng năm và dự kiến lền đến 130 triệu người mắc vào năm 2050 [1]. Nguyên nhân sa sút trí tuệ thường gặp nhất là bệnh Alzheimer chiếm $50-70 \%$ [1]. Đa số bênh nhân Alzheimer sống tại nhà, cân có người chăm sóc và theo dõi, trở thành gánh nă̆ng chăm sóc cho gia đình và xã hội. Các ảnh hưởng về tình cảm và tâm lý của người chăm sóc chủ yếu được biểu hiện bằng gánh nặng khách quan và chủ quan. Gánh nặng khách quan là những ảnh hưởng do những công việc phục vụ bệnh nhân ví dụ như trợ giúp hoạt động hàng ngày (ăn uống, tắm rửa, đi vệ sinh, uống thuốc...) trong khi đó gánh nặng chủ quan là cảm nhận của người chăm sóc về gánh nặng [2]. Thang đánh giá gánh nặng Zarit (Zarit Burden Inventory - ZBI) được phát triển gồm 22 câu hỏi tự đánh giá, điểm càng cao tương ứng với gánh nặng càng lớn. ZBI đã được Việt hóa và sử dụng với độ tin cậy cao [3]. Bệnh viện Lão khoa Trung ương có chương trình quản lý chăm sóc và theo 
dõi bệnh nhân sa sút trí tuệ do Alzheimer. Tuy nhiên vấn đề gánh nặng của người chăm sóc (NCS) trong mô hình quản lý bệnh nhân Alzheimer còn chưa được quan tâm. Chúng tôi thực hiện nghiên cứu này với mục tiêu: Mô tả gánh nằng chăm sóc bệnh nhân Alzheimer tại bệnh viện Lão khoa Trung ương năm 2020 2021 và một số yếu tố liên quan.

\section{II. ĐỐI TƯợNG VÀ PHƯƠNG PHÁP NGHIÊN CỨU}

2.1. Đối tượng nghiên cứu. Nghiên cứu thực hiện trên 52 trường hợp người chăm sóc bệnh nhân đã được chẩn đoán xác định Alzheimer theo tiêu chuẩn DSM IV-TR điều trị nội trú tại khoa Thân kinh và Bệnh Alzheimer, Bệnh viện Lão khoa Trung ương nẳm 2020 - 2021.

2.2. Phương pháp nghiên cứu: Mô tả cắt ngang, lấy mẫu thuận tiện

\section{Bảng 1. Thang điểm Zazit}

Hướng dẫn đôí với người chăm sóc: Những câu hỏi dưới đây phản ánh mức độ cảm nhận khi phải chăm sóc người bệnh. Sau mỗi vấn đề, hãy khoanh tròn vào câu trả lời mà ông/bà cho là đúng nhất (theo mức độ cảm nhận)

\begin{tabular}{|c|c|c|c|c|c|}
\hline \multirow[b]{2}{*}{ Câu hỏi } & \multicolumn{5}{|c|}{ TRÁ LƠI } \\
\hline & $\begin{array}{l}\text { Không } \\
\text { bao giờ }\end{array}$ & $\begin{array}{l}\text { Hiếm } \\
\text { khi }\end{array}$ & $\begin{array}{l}\text { Thinh } \\
\text { thoảng }\end{array}$ & $\begin{array}{l}\text { Khá } \\
\text { thường } \\
\text { xuyên }\end{array}$ & $\begin{array}{l}\text { Luôn } \\
\text { luôn }\end{array}$ \\
\hline $\begin{array}{l}\text { 1. Ông/bà có cảm thấy người bệnh đòi hỏi phục vụ } \\
\text { nhiều hơn nhu cầu không? }\end{array}$ & 0 & 1 & 2 & 3 & 4 \\
\hline $\begin{array}{l}\text { 2. Có phải ông/bà cảm thấy như vâyy vì mình phải } \\
\text { dành hết thời gian cho người bệnh mà không còn thời } \\
\text { gian dành cho bản thân không? }\end{array}$ & 0 & 1 & 2 & 3 & 4 \\
\hline $\begin{array}{l}\text { 3. Ông/bà có cảm thấy căng thằng giữa việc chăm sóc } \\
\text { người bệnh và cố gắng thực hiện nghĩa vụ đối với gia } \\
\text { đình hoặc công việc không? }\end{array}$ & 0 & 1 & 2 & 3 & 4 \\
\hline $\begin{array}{l}\text { 4. Ông/bà có cảm thấy bị rắc rối vì hành vi của người } \\
\text { bệnh không? }\end{array}$ & 0 & 1 & 2 & 3 & 4 \\
\hline $\begin{array}{l}\text { 5. Ông/bà có cảm thấy bực bội khi phải ở bên cạnh } \\
\text { người bệnh không? }\end{array}$ & 0 & 1 & 2 & 3 & 4 \\
\hline $\begin{array}{l}\text { 6. Ông/bà có cảm thấy người bệnh làm ảnh hưởng xấu } \\
\text { đến mối quan hệ hiện nay của ông/bà với các thành } \\
\text { viên khác trong gia đình hoặc với bạn bè không? }\end{array}$ & 0 & 1 & 2 & 3 & 4 \\
\hline $\begin{array}{l}\text { 7. Ông/bà có cảm thấy lo lắng về những nguy cơ sẽ } \\
\text { xảy ra đối với người bệnh không? }\end{array}$ & 0 & 1 & 2 & 3 & 4 \\
\hline $\begin{array}{l}\text { 8. Ông/bà có cảm thấy người bệnh bị phụ thuộc vào } \\
\text { ông/bà không? }\end{array}$ & 0 & 1 & 2 & 3 & 4 \\
\hline $\begin{array}{l}\text { 9. Ông/bà có cảm thấy căng thằng khi phải ở bên } \\
\text { cạnh người bệnh không ? }\end{array}$ & 0 & 1 & 2 & 3 & 4 \\
\hline $\begin{array}{l}\text { 10. Ông/bà có cảm thấy sức khỏe của mình bị giảm } \\
\text { sút vì phải chăm sóc người bệnh không? }\end{array}$ & 0 & 1 & 2 & 3 & 4 \\
\hline $\begin{array}{l}\text { 11. Ông/bà có cảm thấy bị giảm bớt cuộc sống riêng } \\
\text { tư của mình vì phải chăm sóc người bệnh không? }\end{array}$ & 0 & 1 & 2 & 3 & 4 \\
\hline $\begin{array}{l}\text { 12. Ông/bà có cảm thấy cuộc sống xã hội của mình bị } \\
\text { giảm bớt vì phải chăm sóc người bệnh không? }\end{array}$ & 0 & 1 & 2 & 3 & 4 \\
\hline
\end{tabular}

Các biến số và chỉ số thu thập theo mẫu bệnh án nghiên cứu, bao gôm:

+ Thông tin chung của người bệnh và người chăm sóc

+ Đánh giá mức độ nặng và ảnh hưởng của triệu chứng đến người chăm sóc theo trắc nghiệm đánh giá trạng thái tâm thân NPI, các dấu hiệu rối loạn tâm thân và hành vi (BPSD)

+ Đánh giá gánh nặng chăm sóc của người chăm sóc bằng sử dụng thang điểm Zarit (Zarit Burden Interview-ZBI) (Bảng 1) với tổng điểm từ 0 đến 88 điểm với các mức đô: từ 0 đến 20 điểm: không có hoặc có gánh nặng nhẹ; 21 đến 40 điểm: gánh nặng mức độ trung bình; 41 đến 60 điểm: gánh nặng nghiêm trọng; 61 đến 88 điểm: gánh nặng rất nghiêm trọng. 


\begin{tabular}{|c|c|c|c|c|c|}
\hline $\begin{array}{l}\text { 13. Ông/bà có cảm thấy bất tiên khi có nhiều bạn bè } \\
\text { đến thăm người bệnh không? }\end{array}$ & 0 & 1 & 2 & 3 & 4 \\
\hline $\begin{array}{l}\text { 14. Ông/bà có cảm thấy dường như người bênh trông } \\
\text { đợi ông/bà chăm sóc nếu như người bệnh chỉ có thể } \\
\text { nhờ một người chăm sóc duy nhất? }\end{array}$ & 0 & 1 & 2 & 3 & 4 \\
\hline $\begin{array}{c}\text { 15. Ông/bà có cảm thấy mình không có đủ tiền để } \\
\text { chăm sóc người bệnh thêm vào những khoản chi tiêu } \\
\text { của mình không? }\end{array}$ & 0 & 1 & 2 & 3 & 4 \\
\hline $\begin{array}{l}\text { 16. Ông/bà có cảm thấy mình không thể chăm sóc } \\
\text { người bệnh lâu dài hơn nữa không? }\end{array}$ & 0 & 1 & 2 & 3 & 4 \\
\hline $\begin{array}{l}\text { 17. Ông/bà có cảm thấy mất kiểm soát cuộc sống của } \\
\text { mình kể tữ khi người bệnh bị ốm không? }\end{array}$ & 0 & 1 & 2 & 3 & 4 \\
\hline $\begin{array}{l}\text { 18. Ông/bà có mong muốn đế người khác chăm sóc } \\
\text { người bệnh thay cho mình không? }\end{array}$ & 0 & 1 & 2 & 3 & 4 \\
\hline $\begin{array}{l}\text { 19. Ông/bà có cảm thấy không chắc chắn về những } \\
\text { việc mình đã làm cho người bệnh không? }\end{array}$ & 0 & 1 & 2 & 3 & 4 \\
\hline $\begin{array}{l}\text { 20. Ông/bà có cảm thấy cần phải làm nhiều việc hơn } \\
\text { nữa cho người bệnh không? }\end{array}$ & 0 & 1 & 2 & 3 & 4 \\
\hline $\begin{array}{l}\text { 21. Ōng/bà có cảm thấy mình có thể chăm sóc người } \\
\text { bệnh tốt hơn nữa không? }\end{array}$ & 0 & 1 & 2 & 3 & 4 \\
\hline $\begin{array}{l}\text { 22. Nói chung, ông/bà cảm thấy gánh nă̆ng chăm sóc } \\
\text { người bệnh như thể nào? }\end{array}$ & 0 & 1 & 2 & 3 & 4 \\
\hline
\end{tabular}

2.3. Thời gian và địa điểm nghiên cứu. Nghiên cứu được thực hiện từ tháng 12/2020 đến tháng 5/2021 tại Bệnh viện Lão khoa Trung ương.

2.4. Thu thập và xử lý số liệu. Thu thập số liệu theo mẫu bệnh án nghiên cứu. Nhập và lưu trữ số liệu trên phần mềm Epidata 3.1 ; xử lý số liệu bằng các phương pháp thống kê y học trên phần mềm Stata 12.0.

2.5. Đao đức nghiên cứu. Nghiên cứu được thực hiện với sự đồng ý tham gia của người chăm sóc và người bệnh, Tất cả các thông tin cá nhân và bệnh tật được giữ bí mật và chỉ phục vụ mục đích nghiên cứu. Người chăm sóc có quyền dừng tham gia hoặc rút khỏi nghiên cứu bất cứ lúc nào.

\section{KẾT QUẢ NGHIÊN CỨU}

Bảng 3. Một số yêu tố liên quan đến gánh nặng chăm sóc

\begin{tabular}{|c|c|c|c|c|c|}
\hline \multicolumn{6}{|c|}{ 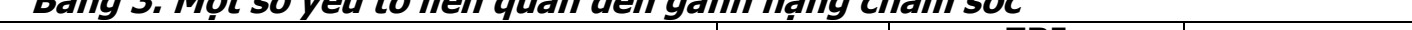 } \\
\hline \multirow{2}{*}{\multicolumn{2}{|c|}{ Yếu tố }} & \multirow{3}{*}{$\begin{array}{c}\mathbf{n} \\
18 \\
\end{array}$} & \multicolumn{2}{|c|}{$\overline{\bar{Y}}$ ZBI } & \multirow{4}{*}{$\frac{\mathbf{p}}{0,3055}$} \\
\hline & & & $X$ & SD & \\
\hline \multirow{2}{*}{ Giới } & Nam & & 44,3 & 4,0 & \\
\hline & Nữ & 34 & 41,8 & 3,0 & \\
\hline \multirow{4}{*}{ Tuổi } & $<50$ & 19 & 40,6 & 17,9 & \multirow{4}{*}{0,412} \\
\hline & $50-59$ & 11 & 31,4 & 16,7 & \\
\hline & $60-69$ & 8 & 47,5 & 16,4 & \\
\hline & $\geq 70$ & 14 & 51,5 & 11,4 & \\
\hline \multirow{4}{*}{$\begin{array}{c}\text { Quan hệ của } \\
\text { NCS với bệnh } \\
\text { nhân }\end{array}$} & NCS là vợ/chồng & 20 & 48,5 & 15,2 & \multirow{4}{*}{0,901} \\
\hline & NCS là con trai/con gái & 13 & 39,5 & 16,7 & \\
\hline & NCS là con dâu/con rế & 17 & 37,3 & 18,4 & \\
\hline & Khác & 2 & 51 & 17,0 & \\
\hline
\end{tabular}

Nghiên cứu thực hiện trên 52 trường hợp người chăm sóc bệnh nhân Alzheimer có đô tuổi thu được kết quả như sau:

Bảng 2. Chỉ số gánh năng chăm sóc ZBI

\begin{tabular}{|c|c|c|}
\hline Phân loại mức độ & $\mathbf{n}$ & Tỷ lệ \% \\
\hline Không hoặc gánh nặng nhẹ & 7 & 13,5 \\
\hline Gánh nặng trung bình & 15 & 28,8 \\
\hline $\begin{array}{c}\text { Gánh nă̆ng nghiêm trọng và } \\
\text { rất nghiêm trọng }\end{array}$ & 30 & 57,7 \\
\hline Tống & $\mathbf{5 2}$ & $\mathbf{1 0 0}$ \\
\hline
\end{tabular}

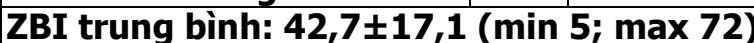

Gánh nă̆ng chăm sóc theo thang điếm ZBI trung bình là $42,7 \pm 17,1$ điểm, chủ yếu gánh nặng ở mức độ nghiêm trọng và rất nghiêm trọng (chiếm 57,7\%). trung bình $57,4 \pm 14,2$, chủ yếu là nữ $(65,4 \%)$ 


\begin{tabular}{|c|c|c|c|c|c|}
\hline \multirow{3}{*}{$\begin{array}{l}\text { Thời gian } \\
\text { chăm sóc } \\
\text { (giờ/ngày) }\end{array}$} & $1-2^{1}$ & 6 & 18,7 & 11,9 & \multirow{3}{*}{$\begin{array}{c}0,317 ; P^{12}=0,0762 \\
P^{13}=0,000 \\
p^{23}=0,0067\end{array}$} \\
\hline & $2-3^{2}$ & 7 & 33 & 19,9 & \\
\hline & $>4^{3}$ & 39 & 48,1 & 13,1 & \\
\hline \multirow{2}{*}{$\begin{array}{l}\text { Là người chăm } \\
\text { sóc duy nhất }\end{array}$} & Có & 24 & 48,1 & 14,3 & \multirow{2}{*}{0,0163} \\
\hline & Không & 28 & 38,0 & 18,1 & \\
\hline \multirow{3}{*}{ Giai đoạn SSTT } & Nhe $^{1}$ & 7 & 13,7 & 6,5 & \multirow{3}{*}{$\begin{array}{c}0,169 ; P^{12}=0,000 \\
\mathrm{P}^{13}=0,000 \\
\mathrm{p}^{23}=0,0042\end{array}$} \\
\hline & Vừa $^{2}$ & 27 & 43,0 & 13,1 & \\
\hline & Nặng ${ }^{3}$ & 18 & 53,4 & 11,4 & \\
\hline \multirow{4}{*}{$\begin{array}{c}\text { Thời gian mắc } \\
\text { bệnh }\end{array}$} & 6 tháng -1 năm ${ }^{1}$ & 4 & 21,8 & 24,0 & \multirow{4}{*}{$\begin{array}{c}0,287 ; \mathrm{p}^{12}=0,0133 \\
\mathrm{p}^{13}=0,0023 \\
\mathrm{p}^{23}=0,0104\end{array}$} \\
\hline & Trên $1-5$ năm ${ }^{2}$ & 37 & 41,6 & 15,6 & \\
\hline & Trên 5 - 10 năm ${ }^{3}$ & 10 & 54,3 & 11,8 & \\
\hline & Trên 10 năm ${ }^{4}$ & 1 & 40 & & \\
\hline
\end{tabular}

$\mathrm{P}^{12}$ : sự khác biệt đặc điếm ${ }^{1}$ và ${ }^{2} ; \mathrm{P}^{13}$ : sự khác biệt đặc điêm ${ }^{1}$ và ${ }^{3} ; \mathrm{P}^{23}$ : sự khác biệt đặc điếm ${ }^{2}$ và ${ }^{3}$

Gánh nặng chăm sóc liên quan có ý nghĩa thống kê $(p<0,05)$ theo thời gian chăm sóc bệnh nhân/ngày, tình trạng là người chăm sóc duy nhất, giai đoạn SSTT và thời gian mắc bệnh.

Bảng 4. Một sồ đặc điểm triệu chứng của người bệnh liên quan đến gánh nặng chăm sóc Triệu chứng

\begin{tabular}{|c|c|c|c|c|c|}
\hline \multicolumn{2}{|l|}{ Triệiu chứng } & $\mathbf{n}$ & $\%$ & ZBI & \multirow{3}{*}{ p } \\
\hline \multirow{2}{*}{ Giảm trí nhớ } & Có & 52 & 100 & 42,7 & \\
\hline & Không & 0 & 0 & 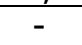 & \\
\hline \multirow{2}{*}{ Giảm định hướng không gian } & Có & 52 & 100 & 42,7 & \multirow[b]{2}{*}{-} \\
\hline & Không & 0 & 0 & - & \\
\hline \multirow{2}{*}{ Giảm định hướng thời gian } & Có & 52 & 100 & 42,7 & \multirow[b]{2}{*}{ - } \\
\hline & Không & 0 & 0 & - & \\
\hline \multirow{2}{*}{ Giảm nhận biết } & Có & 49 & 94,2 & 43,7 & \multirow{2}{*}{0,0379} \\
\hline & Không & 3 & 5,8 & 25,7 & \\
\hline \multirow{2}{*}{ Giảm sự chú ý } & Có & 48 & 92,3 & 45,0 & \\
\hline & Không & 4 & 7,7 & 14,0 & \\
\hline \multirow{2}{*}{ Giảm tư duy } & Có & 50 & 96,2 & 43,5 & \multirow{2}{*}{0,0336} \\
\hline & Không & 2 & 3,8 & 21,0 & \\
\hline \multirow{2}{*}{ Giảm tính toán } & Có & 45 & 86,5 & 47,2 & \multirow{2}{*}{0,0000} \\
\hline & Không & 7 & 13,5 & 13,7 & \\
\hline \multirow{2}{*}{ Giảm ngôn ngữ } & Có & 32 & 61,5 & 42,7 & \multirow{2}{*}{0,0033} \\
\hline & Không & 20 & 39,5 & 12,9 & \\
\hline \multirow{2}{*}{ Giảm hoạt động hàng ngày } & Có & 45 & 86,5 & 47,2 & \multirow{2}{*}{0,0000} \\
\hline & Không & 7 & 13,5 & 13,7 & \\
\hline
\end{tabular}

Sự xuất hiện của tất cả các triệu chứng giảm nhận biết, giảm sự chú ý, giảm tư duy, tính toán, giảm ngôn ngữ và hoạt động hàng ngày có liên quan có ý nghĩa thống kê đến gánh nặng chăm sóc $(\mathrm{p}<0,05)$

Bảng 5. Một số đặc điểm BPSD liên quan đên gánh nặng chăm sóc

\begin{tabular}{|c|c|c|c|c|c|}
\hline \multirow{2}{*}{\multicolumn{2}{|c|}{ NPI }} & \multirow{2}{*}{$\mathbf{n}$} & \multirow{2}{*}{$\%$} & \multicolumn{2}{|c|}{ Sự có mắt của triệu chứng } \\
\hline & & & & ZBI $\bar{X}$ & $\mathbf{p}$ \\
\hline \multirow{2}{*}{ Hoang tưởng } & Có & 20 & 38,5 & 47,9 & \multirow{2}{*}{0,04} \\
\hline & Không & 32 & 61,5 & 39,4 & \\
\hline \multirow{2}{*}{ Ảo giác } & Có & 15 & 28,9 & 47,5 & \multirow[b]{2}{*}{0,0964} \\
\hline & Không & 37 & 71,1 & 40,7 & \\
\hline \multirow{2}{*}{ Trâm cảm } & Có & 24 & 46,2 & 45,7 & \multirow{2}{*}{0,1182} \\
\hline & Không & 28 & 53,8 & 40,0 & \\
\hline \multirow{2}{*}{ Lo âu } & Có & 38 & 73,1 & 41,2 & \multirow{2}{*}{0,1835} \\
\hline & Không & 14 & 26,9 & 46,2 & \\
\hline \multirow{2}{*}{ Hưng phấn } & Có & 26 & 50,0 & 39,3 & \multirow{2}{*}{0,0776} \\
\hline & Không & 26 & 50,0 & 46,0 & \\
\hline \multirow[b]{2}{*}{ Vô cảm } & Có & 28 & 53,8 & 44,8 & \multirow[b]{2}{*}{0,1640} \\
\hline & Không & 24 & 46,2 & 40,1 & \\
\hline Kích đông & Có & 38 & 73,1 & 50,6 & 0,0207 \\
\hline
\end{tabular}


VIETNAM MEDICAL JOURNAL N01 - JUNE - 2021

\begin{tabular}{|c|c|c|c|c|c|}
\hline & Không & 14 & 26,9 & 39,7 & \\
\hline \multirow{2}{*}{ Mất ức chế } & Có & 22 & 42,3 & 47,3 & \multirow{2}{*}{0,0477} \\
\hline & Không & 30 & 57,7 & 39,3 & \\
\hline \multirow{2}{*}{ Rối loạn vận động } & Có & 29 & 55,8 & 46,6 & \multirow{2}{*}{0,0321} \\
\hline & Không & 23 & 44,2 & 37,7 & \\
\hline \multirow{2}{*}{ Rối loạn hành vi ban đêm } & Có & 47 & 90,4 & 44,7 & \multirow{2}{*}{0,0031} \\
\hline & Không & 5 & 9,6 & 23,2 & \\
\hline \multirow{2}{*}{ Rối loạn ăn uống } & Có & 39 & 75,0 & 47,8 & \multirow{2}{*}{0,0000} \\
\hline & Không & 13 & 25,0 & 27,2 & \\
\hline
\end{tabular}

Sự xuất hiện của các triệu chứng BPSD gồm: hoang tưởng, kích động, mất ức chế, rối loạn vận động, rối loạn ăn uống và hành vi ban đêm có liên quan có ý nghĩa thống kê đến gánh nặng chăm sóc $(p<0,05)$.

\section{BÀN LUÂN}

Nghiên cứu 52 trường hợp người chăm sóc bệnh nhân Alzheimer cho thẩy gánh nặng chăm sóc trung bình theo thang điểm ZBI là $42,7 \pm$ 17,1 . Trong đó trên $80 \%$ trường hợp có điểm ZBI từ 41 trở lên, tương đương với mức độ trung bình trở lên và có đến $57,7 \%$ trường hợp gánh nặng mức độ nghiêm trọng và rất nghiêm trọng. Kết quả này cao hơn nhiêuu so với nghiên cứu của Nguyễn Thanh Bình năm 2016 ZBI trung bình chỉ 27,07士 18,01 và tỷ lệ mức độ gánh nặng trung bình trở lên thấp hơn với $59,5 \%$. Sự khác biệt này có thể do nghiên cứu của Nguyễn Thanh Bình và cộng sự thực hiện trên đối tượng chăm sóc người bệnh Alzheimer giai đoạn cuối, chăm sóc tại nhà và khám ngoại trú thường xuyên so với nghiên cứu của chúng tôi thực hiện trên người bệnh Alzheimer điều trị nội trú tại Bệnh viện ở tất cả giai đoạn [4]. Kết quả này cũ̃ng tướng tự các nghiên cứu khác trên thế giới như báo cáo tại Mỹ năm 2010 ZBI trung bình là 34,4 $\pm 16,0$ [5] hay tại Nhật Bản năm 2014 ZBI là $32,3 \pm 18,8$ [6] với sự khác biệt về mô hình quản lý và hố trợ, kiến thức - kỹ nắng thực hành chăm sóc của NCS giữa các quốc gia và theo mốc thời gian khác nhau. Mặc dù vậy, kết quả này bước đầu có thể cho thẩy gánh nặng chăm sóc bênh nhân nằm điều trị nội trú cao hơn nhiều so với ngoại trú khi NCS phải dành nhiều thời gian hơn trong bệnh viện cũng như ảnh hưởng của các triệu chứng nặng lên khiến người bệnh cần nhập viện. Như vậy, vấn đề gánh nặng chăm sóc người bệnh Alzheimer cần được quan tâm tiếp cận ngay từ khi chẩn đoán bệnh và điều trị nội trú tại bệnh viện. Đây là một yếu tố quan trọng giúp xây dựng các giải pháp phù hợp hỗ trợ NCS nhằm giảm gánh nặng cũng như nâng cao chất lượng chăm sóc người bệnh.

Tất cả các nghiên cứu trên cũng như kết quả của chúng tôi đều cho thây gánh nặng chăm sóc tăng dần theo giai đoạn Alzheimer và cao nhất ở nhóm chăm sóc bệnh nhân giai đoạn nặng, tương đương với thời gian chăm sóc cần thiết mỗi ngày tăng lên và thời gian mắc bệnh dài hơn $(p<0,05)$. Gánh nặng chăm sóc tăng 1,76 lần nếu thời gian chăm sóc tăng từ $1-2$ giờ lên 2 3 giờ/ngày và tăng 2,57 lần nếu thời gian chăm sóc kéo dài trên 4 giờ/ngày.

Một nghiên cứu đa trung tâm tại Mỹ, Trung Quốc và Ấn Độ cho thây cứ tăng mỗi 1 giờ cho việc chăm sóc sẽ làm tăng thêm 1 điểm ZBI [7]. Khi tình trạng bệnh càng nặng, sự xuất hiện của tất cả các triệu chứng giảm nhận biết, giảm sự chú ý, giảm tư duy, tính toán, giảm ngôn ngữ và hoạt động hàng ngày đều làm tăng gánh nặng chẳm sóc có ý nghĩa thống kê so với nhóm không có các triệu chứng này $(p<0,05)$. Tương tự khi xuất hiện các triệu chứng BPSD bao gồm: hoang tưởng, kích động, mất ức chế, rối loạn vận động, rối loạn ăn uống và hành vi ban đêm cũ̃ng làm điểm ZBI trung bình cao hơn so với nhóm chăm sóc người bệnh không có BPSD $(p<0,05)$. Các đặc điểm triệu chứng bệnh kể trên dẫn đến nhu cầu cấp thiết cần người chăm sóc phải theo dõi sát sao hơn và dành nhiều thời gian hơn bên canh người bệnh dẫn đến gánh nặng chăm sóc tăng lên. Mặt khác, việc là NCS dưy nhất của người bệnh cũ̃ng trở thành gánh nặng lớn với điểm ZBI trung bình 48,1 cao hơn nhiều so với NCS không phải là người chăm duy nhất - ZBI trung bình chỉ 38,0 điểm. Kết quả này cũng tương tự nghiên cứu của Nguyễn Thanh Bình [4], Kamiya [6], Prince [8] khi nhận thây có mối tương quan về gánh nặng chăm sóc với thời gian bị bênh và thời gian cần chăm sóc người bệnh mổi ngày tương ứng với các triệu chứng Alzheimer giai đoạn vừa và nặng. Càng nhiều người cùng chăm sóc thì gánh nặng càng giảm, trung bình cứ có hơn một người chăm sóc thì ZBI giảm đi 0,5 điểm [7]. Khi xét đến mối quan hệ của NCS và người bệnh, kết quả cho thấy NCS là bạn đời (vợ/chồng) có xu hướng gánh nặng cao hơn nhiêu so với khi NCS là con cái. tương tự kết quả của Park (Hàn Quốc) [8] 
hay nghiên cứu của Prine[7] cho thấy khu vực các nước Châu Á thường có xu hướng khác biệt này. Kết quả này có thể liên quan đến đặc điểm văn hóa và vai trò trong chăm sóc của các đối tượng NCS khác nhau. NCS là vợ/chồng thường có tuổi cao hơn, tuổi càng cao gánh nặng càng lớn. Mặt khác, họ cũng thường là người chăm sóc duy nhất và cần phải dành nhiều thời gian chăm sóc hơn so với nhóm còn lại. Đặc điểm văn hóa châu Á coi việc chăm sóc cha mẹ là nghĩa vụ, ngược lại so với các nước Âu - Mỹ, việc chăm sóc người già đối với con/cháu là gánh nặng lớn hơn. Tóm lại đối tượng dễ tổn thương trong số những người chăm sóc bệnh nhân Alzheimer là bạn đời, cao tuổi, là người chăm sóc duy nhất và người bệnh Alzheimer ở giai đoạn vừa và nặng với các triệu chứng BPSD. Để làm giảm gánh nặng cho NCS và nâng cao hiệu quả chăm sóc người bệnh, cần định hướng hỗ trợ cho nhóm đối tượng này hiểu rõ về các triệu chứng và tiến triển của bệnh Alzheimer, cách chăm sóc và đối phó tình huống, chia sẻ công việc và cần thiết phải xây dựng chương trình hổ trợ giảm gánh nặng cho NCS song song với quản lý và điều trị bệnh nhân.

\section{KẾT LUẬN}

Gánh nặng của NCS bệnh nhân Alzheimer theo thang điểm Zarit là 42,7 điểm, trên $80 \%$ trường hợp gánh nặng mức độ trung bình trở lên. Gánh nặng chăm sóc có mối liên quan có ý nghĩa thống kê $(p<0,05)$ với thời gian chăm sóc bệnh nhân/ngày; thời gian mắc bệnh; giai đoạn sa sút trí tuệ; sự xuất hiện triệu chứng các triệu chứng giảm nhận biết, giảm sự chú ý, giảm tư duy, tính toán, giảm ngôn ngữ và hoạt động hàng ngày và các triệu chứng BPSD như hoang tưởng, mất ức chế, rối loạn vận động, rối loạn ăn uống và hành vi ban đêm.

\section{TÀl LIẸU THAM KHẢO}

1. WHO (2018). Dementia: a public health priority. World Health Organization.

2. Baumgarten M., Battista R.N., Infante-Rivard C. và cộng sự. (1992). The psychological and physical health of family members caring for an elderly person with dementia. Journal of Clinical Epidemiology, 45(1), 61-70.

3. Nguyễn Bích Ngọc, Đố Thi Khánh Hỷ, Kim Bảo Giang và cộng sự. (2013). Đánh gia gánh nặng của người chăm sóc trong bệnh Alzheimer. Tạp chí Y học dự phòng, 5(151), 88-94.

4. Nguyển Thianh Bình, Nguyễn Trọng Hưng, và Pham Thắng (2016). Gảnh nặng chăm sóc bênh nhẩn Alzheimer giai đoạn cuối và các yếu tố liên quan. Tạp chí nghiên cứu y học, $\mathbf{1 0 0}(\mathbf{2}), 148-155$.

5. Mohamed S., Rosenheck R., Lyketsos C.G. và cộng sự. (2010). Caregiver Burden in Alzheimer Disease: Cross-Sectional and Longitudinal Patient Correlates. The American Journal of Geriatric Psychiatry, 18(10), 917-927.

6. Kamiya M., Sakurai T., Ogama N. và cộng sự. (2014). Factors associated with increased caregivers' burden in several cognitive stages of Alzheimer's disease: Caregivers' burden in Alzheimer's disease. Geriatrics \& Gerontology International, 14, 45-55.

7. Prince M., Brodaty H., Uwakwe R. và cộng sư. (2012). Strain and its correlates among carers of people with dementia in low-income and middle-income countries. A 10/66 Dementia Research Group population-based survey. Int J Geriatr Psychiatry, 27(7), 670-682.

8. Park M., Sung M., Kim S.K. và cộng sự. (2015). Multidimensional determinants of family caregiver burden in Alzheimer's disease. Int Psychogeriatr, 27(8), 1355-1364.

\section{KẾT QUẢ PHẪU THUÂT ÍT XÂM LẤN Có NộI SOI HỖ TRỢ, TIM ĐÂPP ĐIỀU TRI THÔNG LIẾN NHĨ TẠI BÊ̂NH VIỆN HỮU NGHỊ VIỆT ĐỨC}

\section{TÓM TẮT}

Mục tiêu: Mô tả đặc điểm kỹ thuật của phương pháp phẫu thuật ít xâm lấn có nội soi hỗ trợ vá thông liên nhĩ qua đường mở ngực phải, tim đập và đánh giá kết quả áp dụng phẫu thuật này tại bệnh viện Hữu

${ }^{1}$ Bệnh viện Hữu Nghị Việt Đức

${ }^{2}$ Đai hoc Y Hà Nôi

Chịu trách nhiệm chính: Phùng Duy Hồng Sơn

Email: hongsony81@yahoo.com

Ngày nhận bài: 16.3.2021

Ngày phản biên khoa học: 11.5.2021

Ngày duyệt bài: 19.5.2021
Phan Nhật Trung², Phùng Duy Hồng Sơn ${ }^{1,2}$

nghị Việt Đức. Đối tượng và phương pháp nghiên cứu: Nghiên cứu mô tả hồi cứu các bệnh nhân đước phẫu thuật vá thông liên nhĩ sử dụng phương pháp phẫu thuất ít xâm lấn có nội soi hỗ trợ, qua đường mở ngực phải, tim đập tại Trung tâm Tim mạch và Lông ngực bệnh viên Hữu Nighi Việt Đức từ 08/2017 đên 12 /2020. Có 35 bệnh nhân nghiên cứu, nữ giới 26 $(77,1 \%)$. Tuổi trung bình $41 \pm 13$ tuổi $(16-64)$. Kết quá: Không có bệnh nhân tử vong sau mổ. Thời gian tuần hoàn ngoài cơ thể $40 \pm 14$ phút $(18-82)$, thời gian phẫu thuật $143 \pm 22$ phút (100-180). Thời gian thở máy $7,1 \pm 0,4$ giờ $(1-48)$, thời gian nằm viện sau mổ $9 \pm 3$ ngày (6-15). Siêu âm sau mổ cho kết quả tốt, có 1 bệnh nhân còn shunt tồn lưu. Biến chứng: có 2 